\title{
Effects of C Element on Microstructure and Mechanical Behavior of AICrFeMnNi High-entropy Alloy
}

\author{
Chunming $\mathrm{Li}^{\mathrm{a}}$, Bilei Wang ${ }^{\mathrm{b}}$, Yunhu Zhang ${ }^{\mathrm{c}}$, Changjiang Song ${ }^{\mathrm{d}, \star}$ and Qijie Zhai ${ }^{\mathrm{e}}$ \\ State Key Laboratory of Advanced Special Steel \& \\ Shanghai Key Laboratory of Advanced Ferrometallurgy \&
}

School of Materials science and Engineering,Shanghai University, Shangai, China

alichunming1227@163.com, bwangbilei@i.shu.edu.cn, 'zhangyunhu.zyh@163.com, driversxiao@163.com, equzhai@shu.edu.cn

${ }^{*}$ Corresponding author

Keywords: High entropy alloy, Light element, Microstructure, Mechanical properties.

Abstract. The $\mathrm{AlCrFeMnNiC}_{\mathrm{x}}$ ( $\mathrm{x}$ values in molar ratio, $\mathrm{x}=0,0.08,0.17$ and 0.25 ) were designed and prepared by adding nonmetallic carbon element into the high entropy alloy under near-rapid solidification conditions. The effects of carbon content and heat treatment on microstructure and mechanical properties of $\mathrm{AlCrFeMnNiCx}$ alloy were investigated. Experimental results show that the addition of carbon element can lead to the formation of carbonization besides BCC solid solution. There are also amounts of nanoscale particles and laminated structure formed in the samples. Microstructure of near-rapidly solidified $\mathrm{AlCrFeMnNiCx}$ alloy turns coarse after aging at $600{ }^{\circ} \mathrm{C}$ hold for 3 hours. Addition of carbon decreases yield strength of AlCrFeMnNi alloy, but the compressive fracture strength and plastic strain are improved, especially for the samples at aged state having significantly increased mechanical properties. $\mathrm{AlCrFeMnNiC}_{0.08}$ alloy both in as cast and aged state shows the best compressive fracture strength and plastic strain in the four samples. This experimental study suggests that introduction $\mathrm{C}$ elements into the high-entropy alloy can be a developing direction to enhance the properties of high-entropy alloys.

\section{Introduction}

High-entropy alloys (HEAs) which are different from traditional alloys [1-4] are composed of at least five elements each having an atomic percentage in the range of 5\%-35\% [5]. According to traditional alloy design theories, the more composition elements there are, the more intermetallic compounds will form, but high-entropy alloys only tend to form single phase (fcc or bcc) or simply several phases owing to high-entropy effect [5-8]. In recent years, more and more researchers have carried out their study on high-entropy alloys because of their superior mechanical properties, such as high hardness, good oxidation resistance, high elevated-temperature strength and good age-softening resistance [9-12]. High-entropy alloys have potential applications in molds, tools, chemical and ship structural materials. AlCrFeMnNi alloy is one of the most typical high-entropy alloys systems. Chen et al. replaced $\mathrm{Co}$ with $\mathrm{Mn}$ and removed $\mathrm{Cu}$ in $\mathrm{AlCrCuFeCoNi}$ high-entropy alloys and they got $\mathrm{Al}_{\mathrm{x}} \mathrm{CrMnFeNi}_{0.5}$ high-entropy alloys which have excellent processability and excellent resistance to high-temperature softening and high-temperature hardness [13]. Lee et al. examined the corrosion behaviour of the $\mathrm{Al}_{\mathrm{x}} \mathrm{CrFe}_{1.5} \mathrm{MnNi}_{0.5}$ high-entropy alloys in $\mathrm{H}_{2} \mathrm{SO}_{4}$ and $\mathrm{NaCl}$ solutions and found that the corrosion resistance increased as the concentration of aluminium decreased [14]. Tang et al. investigated the effect of plasma nitriding at $798 \mathrm{~K}\left(525^{\circ} \mathrm{C}\right)$ on microstructures and the mechanical performance of $\mathrm{Al}_{0.3} \mathrm{CrFe}_{1.5} \mathrm{MnNi}_{0.5}$ high-entropy alloys (HEAs) obtained by using cast and wrought processing and attained a peak hardness around HV 1300 near the surface. They also found that the nitrided layer of $\mathrm{Al}_{0.5} \mathrm{CrFe}_{1.5} \mathrm{MnNi}_{0.5}$ high-entropy alloy (HEA) which was plasma nitrided at $525^{\circ} \mathrm{C}$ had a thickness around $75 \mu \mathrm{m}$ and a peak hardness of HV 1250 near the surface [15]. Tsao [16] investigated the effect of aging treatment at $650-750{ }^{\circ} \mathrm{C}$ for $8 \mathrm{~h}$ on the microstructure and microhardness of the $\mathrm{Al}_{0.3} \mathrm{CrFe}_{1.5} \mathrm{MnNi}_{0.5}$ high entropy alloy and they concluded that precipitation phases such as AlNi and $\mathrm{Cr}_{5} \mathrm{Fe}_{6} \mathrm{Mn}_{8}$ in the grain matrix are the main age hardening mechanism. 
As we all known that $\mathrm{Al}$ is lightweight element and good for weight loss of the automobile and energy conservation and emissions reduction. However, the addition of Al element could lead to the formation of single bcc solid solution which severely weakens the tensile ductility because $\mathrm{Al}$ can stabilize the ferritic phase. For example, $\mathrm{Al}_{0.3} \mathrm{CrFe}_{1.5} \mathrm{MnNi}_{0.5}$ alloy in the as-cast consists of $\mathrm{BCC}$ phase and $\mathrm{FCC}$ phase, whereas $\mathrm{Al}_{0.5} \mathrm{CrFe}_{1.5} \mathrm{MnNi}_{0.5}$ alloy in the corresponding states only has a matrix of $\mathrm{BCC}$ phase [17]. The addition of elements with small atomic radii like $\mathrm{C}$ in traditional materials like steel is beneficial to their structure and properties because the interstitial $\mathrm{C}$ can stabilize the face centered cubic phase [18]. In the present paper, we attempt to add $\mathrm{C}$ element into $\mathrm{AlCrFeMnNi}$ alloy to improve its properties and transform bec solid solution into fcc solid solution. The effects of carbon element and heat treatment on microstructure and mechanical properties of equimolar ratio $\mathrm{AlCrFeMnNi}$ alloy are investigated systematically.

\section{Experimental methods}

Alloy ingots with nominal compositions of $\mathrm{AlCrFeMnNiCx}(\mathrm{x}=0,0.08,0.17,0.25)$ were prepared by water-cooled induction coil heating a mixture of ultrasonically cleansed $\mathrm{Al}, \mathrm{Cr}, \mathrm{Fe}, \mathrm{Mn}, \mathrm{Ni}$ and $\mathrm{C}$ (graphite) elements with a purity of above $99.9 \mathrm{wt} \%$ under high purity argon atmosphere. Rectangular ingots in size of $50 \mathrm{~mm} \times 8 \mathrm{~mm} \times 2 \mathrm{~mm}$ were produced by spraying casting the melts into copper molds. Chemical homogeneity was confirmed by repeated melting at least three times. Samples cut from the ingot were homogenized at $600^{\circ} \mathrm{C}$ for $3 \mathrm{~h}$ and then cooling in the furnace. Phase identification and microstructure analyses were then carried out on the as-cast and heat treatment samples. The phases and microstructures were characterized using X-ray diffraction(XRD, Rigaku $\mathrm{D} / \mathrm{max}-2200 \mathrm{X}, \mathrm{Cu} \mathrm{Ka}$ target operated at $40 \mathrm{kV}$ and $60 \mathrm{~mA})$, optical microscopy(OM), scanning electron microscope (SEM, CARL ZEISS SUPRA40). The compressive samples with $2 \mathrm{~mm} \times 2$ $\mathrm{mm} \times 4 \mathrm{~mm}$ rectangular ingots were ground on 2000 grit sand papers.

\section{Results and discussion}

\section{XRD results}

Fig. 1 shows the XRD patterns of $\mathrm{AlCrFeMnNiCx}$ alloys in the as-cast and aged hardening states, respectively. Only diffraction peak corresponding to a $\mathrm{BCC}$ crystal structure is observed in the as-cast $\mathrm{AlCrFeMnNi}$ alloy (see Fig. 1(a)). It indicates that $\mathrm{Al}, \mathrm{Cr}, \mathrm{Fe}, \mathrm{Mn}$, Ni elements distribute in the crystal lattices and form quinary BCC solid solution. The reflections of carbonization appear with the introduction of carbon element. For as cast $\mathrm{AlCrFeMnNiC}_{\mathrm{x}}$ high entropy, the relative intensity of carbonization phase increases with the addition of carbon content, which suggests that the weight fraction of carbonization phase increases. Fig. 1(b) shows the XRD patterns of the AlCrFeMnNiCx HEAs aged at $600^{\circ} \mathrm{C}$ for $3 \mathrm{~h}$. The carbonization phase whose 2 theta is close to 43 degree begins to appear after heat treatment while the intensity of peak of carbonization phase where 2 theta is about 38 degree weakens.
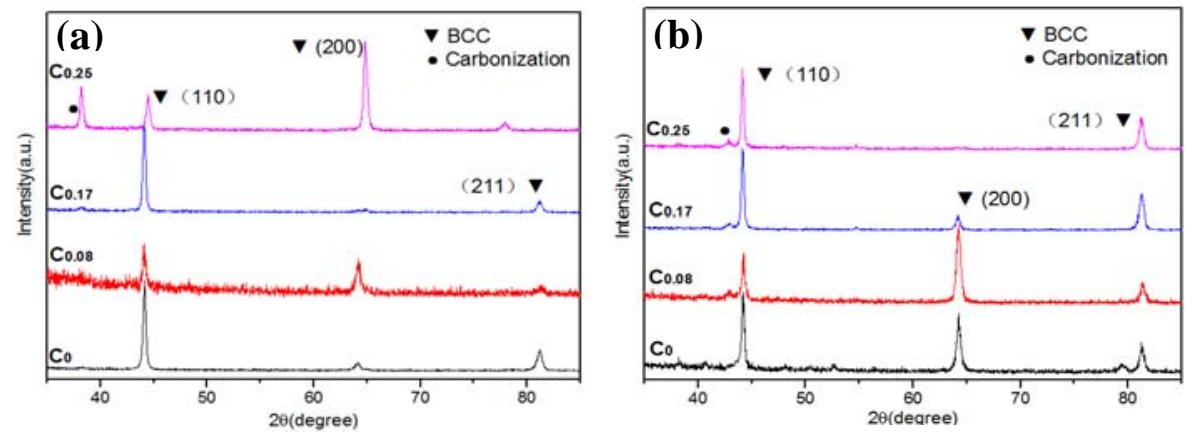

Fig. 1. XRD patterns of $\mathrm{AlCrFeMnNiC}_{\mathrm{x}}(\mathrm{x}=0,0.08,0.17$ and 0.25$)$ : (a) as cast, (b) aged at $600^{\circ} \mathrm{C}$ for $3 \mathrm{~h}$ 


\section{Metallographic structure}

The metallographic photos of as-cast samples are displayed in Figure. 2. The morphology of the four alloys is different from each other. It is found that the as-cast AlCrFeMnNi alloy is consist of round and rod-like structure. According to the results of XRD, the detected phase is mainly bcc crystal structure. The needle-like carbonization appears and becomes sharper with the content of carbon element increases. After heating at $600^{\circ} \mathrm{C}$ for $3 \mathrm{~h}$ of $\mathrm{AlCrFeMnNiCx}$ alloys, the structure of alloys becomes coarse as shown in Fig 3. Considering the role of $\mathrm{C}$ element, it is concluded that $\mathrm{C}$ element has a significant impact on structure of $\mathrm{AlCrFeMnNiCx}$ HEAs.
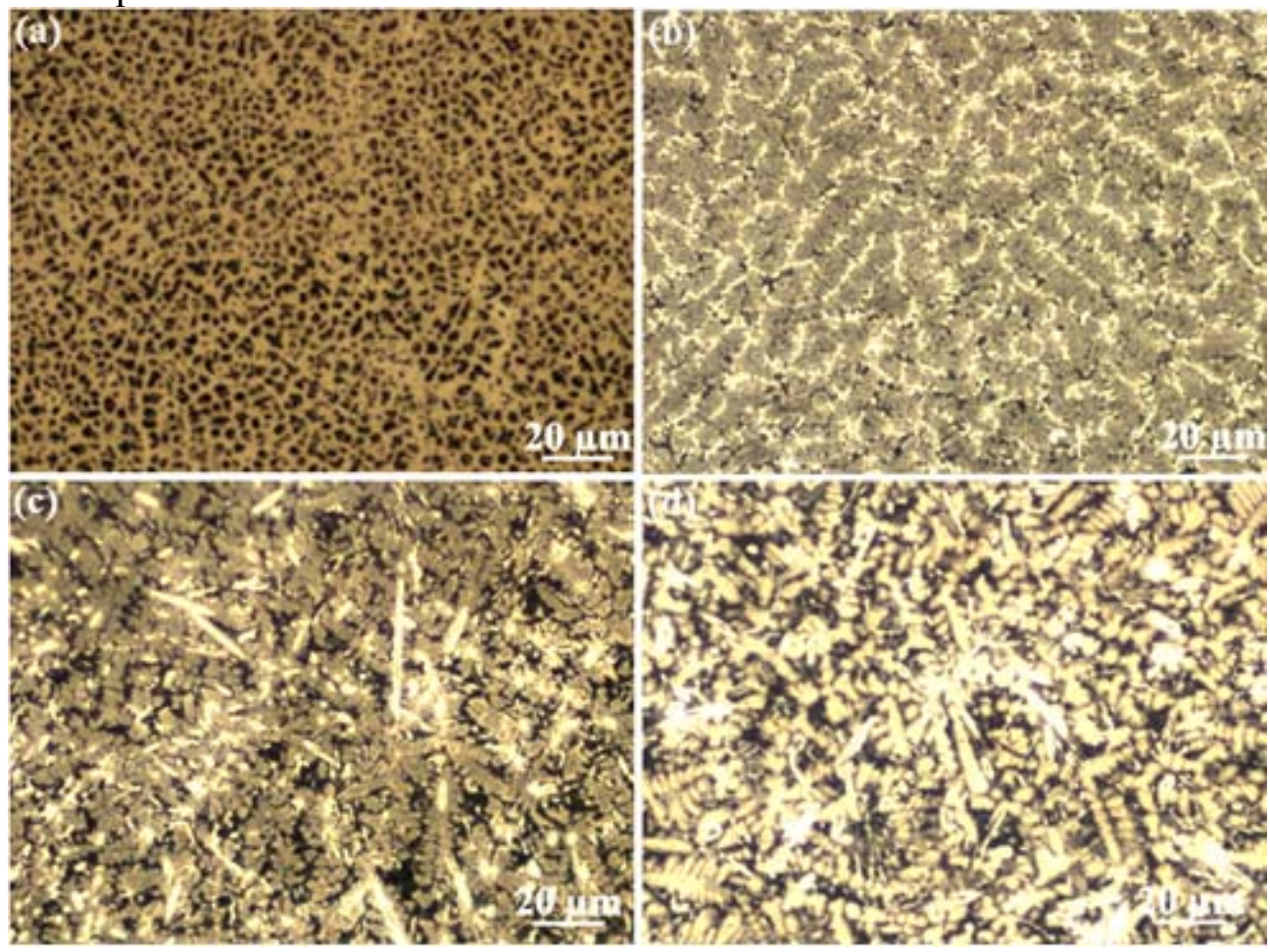

Fig. 2. Metallographic photos of as-cast AlCrFeMnNiCx alloys: (a) 0, (b) 0.08 , (c) 0.17 , (d) 0.25 .
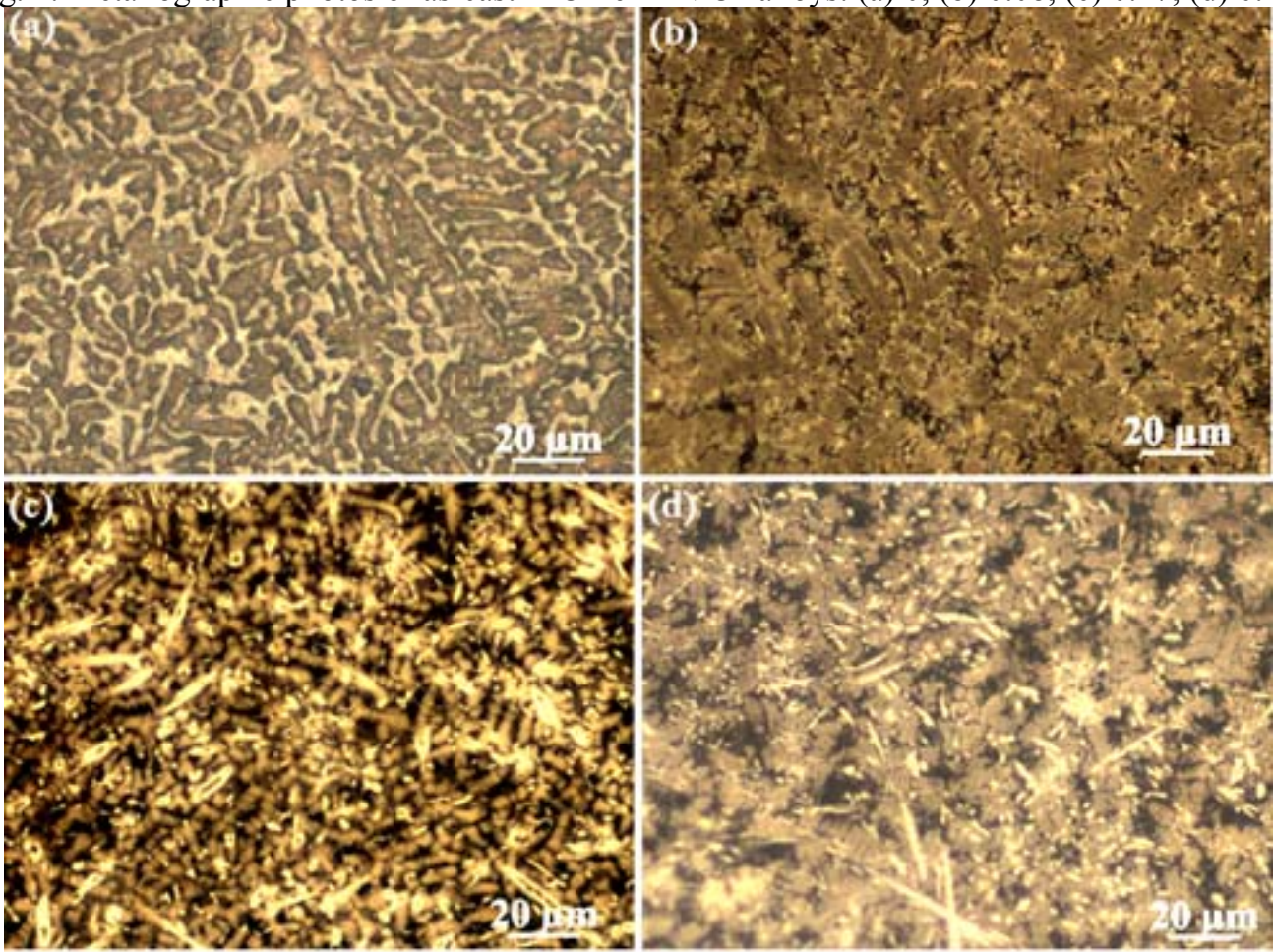

Fig.3. Metallographic photos of AlCrFeMnNiCx alloys aged at $600^{\circ} \mathrm{C}$ for $3 \mathrm{~h}$ : (a) 0 , (b) 0.08 , (c) 0.17 , (d) 0.25 . 


\section{SEM structure}

The secondary electron images of the as-cast $\mathrm{AlCrFeMnNiCx}$ alloys are exhibited in Figure. 4. Figures 4(a), (b), (c), and (d) correspond to the content of carbon of $0,0.08,0.17$, and 0.25 , respectively. Nanoscale particles and laminated structure can be clearly found in Figures 4(a-d), which may be related to the special formation process of high entropy alloys, such as spinodal decomposition. As we all known that in diffusion-controlled phase transformation, the formation of new phases requires cooperative diffusion of many different kinds of atoms to accomplish the partitioning of composition in HEAs. As a result, the diffusion of an atom in a whole-solute matrix would be very different from that in the matrix of conventional alloys. A vacancy in the whole-solute matrix is in fact surrounded and competed by different-element atoms during diffusion. It has been proposed that slower diffusion and higher activation energy would occur in HEAs due to larger fluctuation of lattice potential energy (LPE) between lattice sites. The abundant low-LPE sites can serve as traps and hinder the diffusion of atoms. This leads to the appearance of nanoscale sub-structure [19]. Fig. 5 shows the secondary electron images of aged at $600^{\circ} \mathrm{C} \mathrm{AlCrFeMnNiC}_{\mathrm{x}}$ alloys. Compared with as-cast $\mathrm{AlCrFeMnNiCx}$ alloys, the morphology of alloys does not have obvious change.
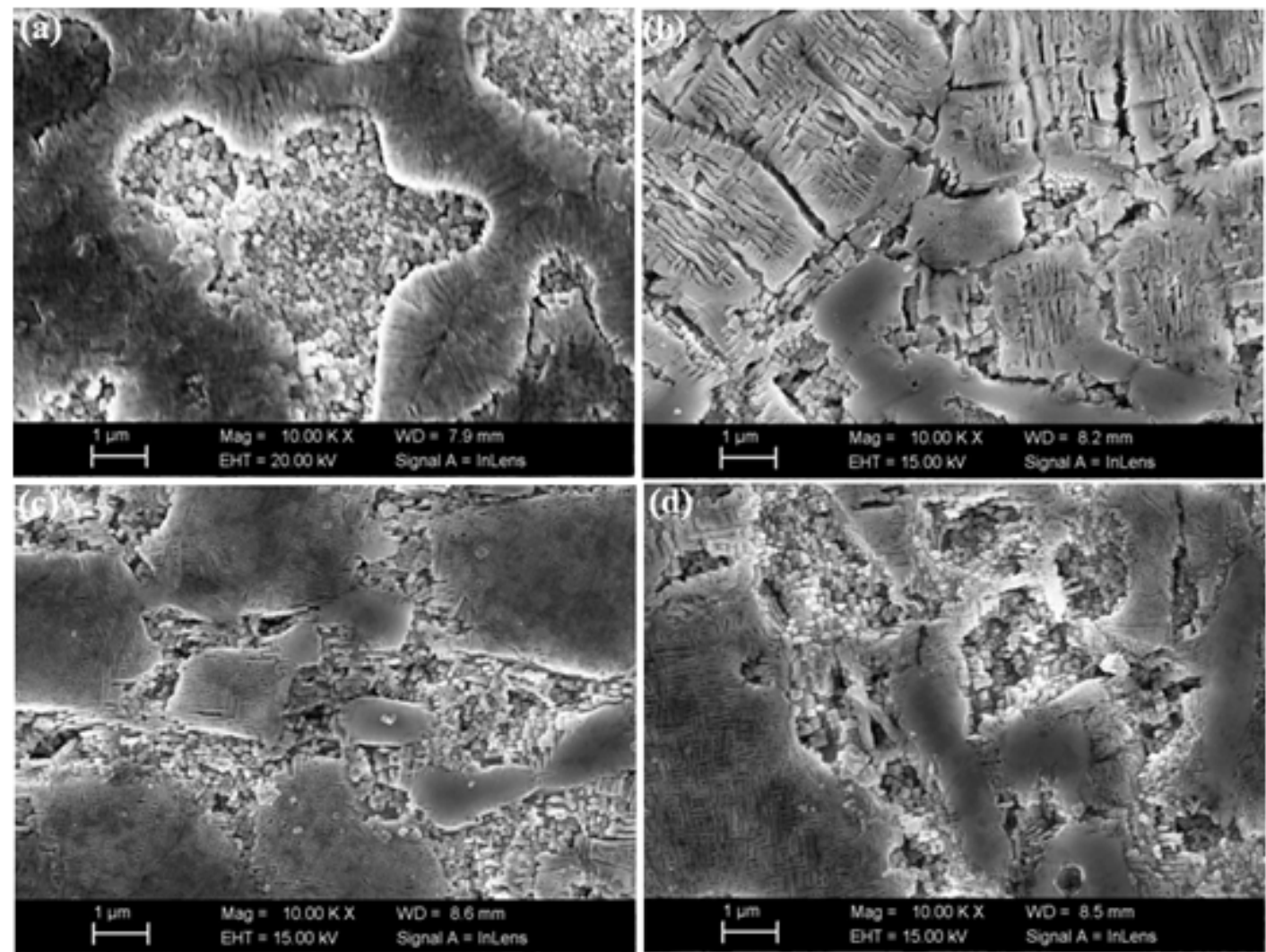

Fig. 4. SEM micrographs of as-cast $\mathrm{AlCrFeMnNiC}_{\mathrm{x}}$ alloys: (a) 0, (b) 0.08, (c) 0.17, (d) 0.25. 

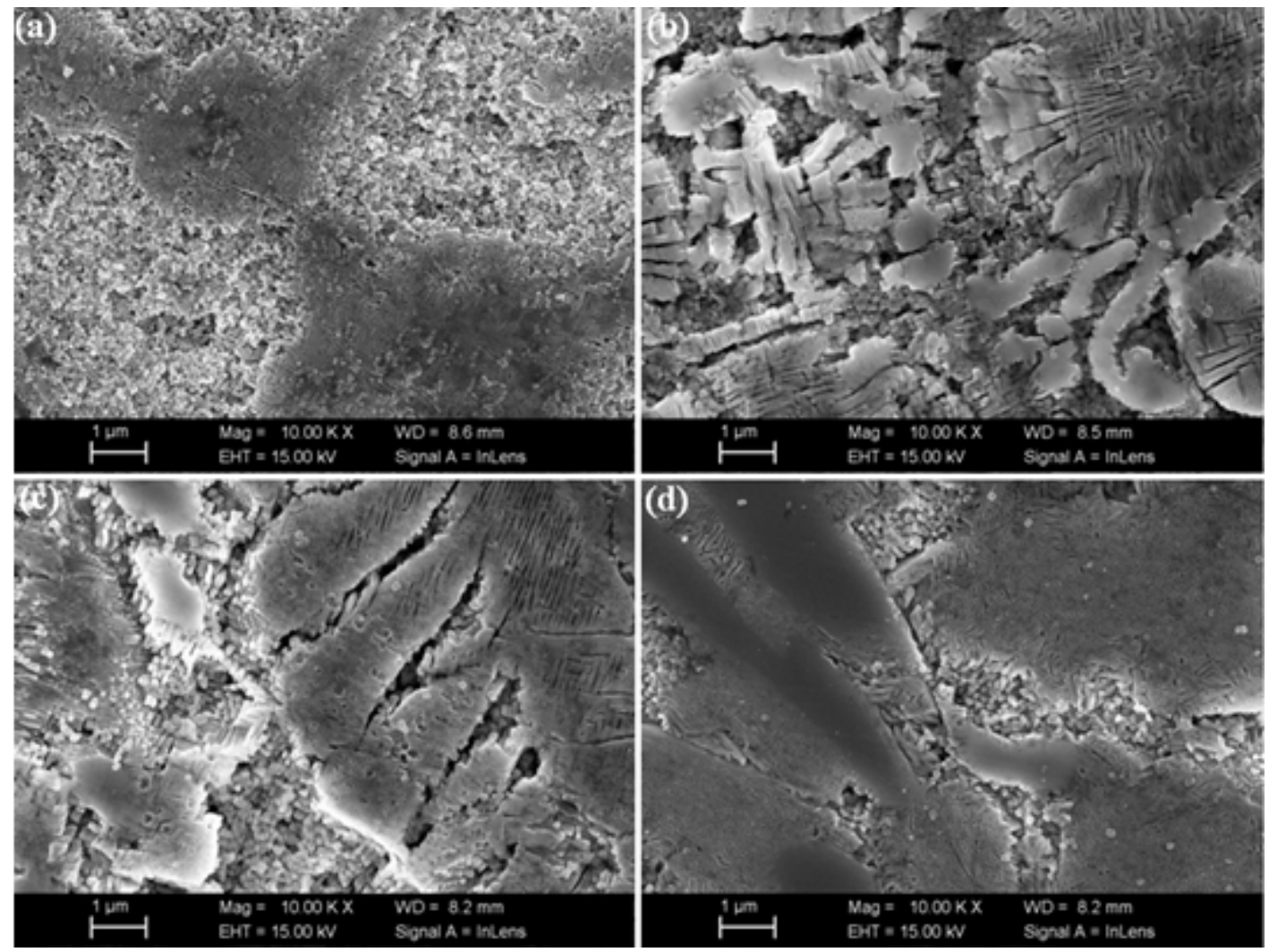

Fig.5. SEM micrographs of $\mathrm{AlCrFeMnNiC}_{\mathrm{x}}$ alloys aged at $600^{\circ} \mathrm{C}$ for $3 \mathrm{~h}$ : (a) 0 , (b) 0.08, (c) 0.17, (d) 0.25.

\section{Mechanical properties}

As shown in Fig. 6, the compressive stress strain curves of $\mathrm{AlCrFeMnNiC}_{\mathrm{x}}$ alloys were measured for as-cast and aged samples at room temperature. The yield strength $\left(\sigma_{y}\right)$, compressive fracture strength $\left(\sigma_{\max }\right)$ and plastic strain limit $\left(\varepsilon_{\mathrm{p}}\right)$ of the alloys are listed in Table 1 . The results indicate that $\sigma_{\mathrm{y}}, \sigma_{\max }$ and $\varepsilon_{\mathrm{p}}$ are not changed linearly with the increase of $\mathrm{C}$ content. In both the as-cast and aged at $600^{\circ} \mathrm{C}$ for $3 \mathrm{~h}$ for $\mathrm{AlCrFeMnNiCx}$ alloys, the addition of $\mathrm{C}$ element decreases the yield strength $\sigma_{\mathrm{y}}$ of $\mathrm{AlCrFeMnNi}$ alloy, but enhances the compressive fracture strength $\left(\sigma_{\max }\right)$ and plastic strain limit $\left(\varepsilon_{\mathrm{p}}\right)$. Especialy for aged state, the addition of $\mathrm{C}$ element can significantly improve the properties of $\mathrm{AlCrFeMnNi}$ alloy. Futhermore, $\mathrm{AlCrFeMnNiC}{ }_{0.08}$ alloy shows excellent compressive fracture strength and plastic strain. For as-cast sample $\sigma_{\max }$ and $\varepsilon_{\mathrm{p}}$ increase from $2613 \mathrm{MPa}, 24.8 \%$ to $2959 \mathrm{MPa}, 30.6 \%$, respectively. For aged samples $\sigma_{\max }$ and $\varepsilon_{\mathrm{p}}$ increase from $2424 \mathrm{MPa}, 18.5 \%$ to $3245 \mathrm{MPa}, 35.3 \%$, respectively.
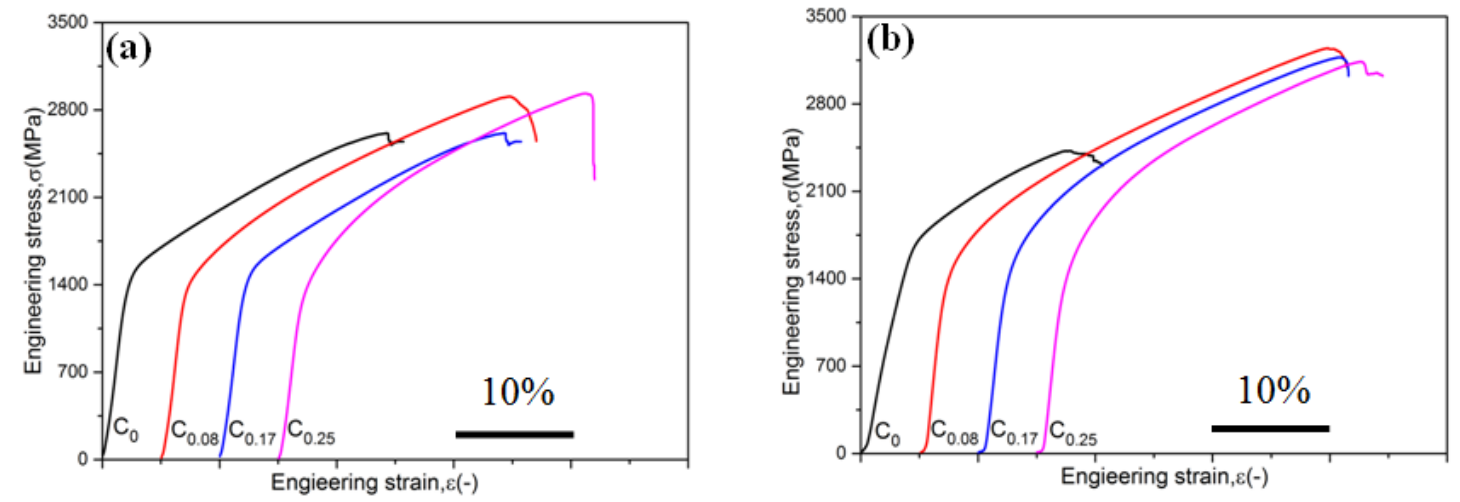

Fig. 6 Compressive stress strain curves of $\mathrm{AlCrFeMnNiC}_{\mathrm{x}}(\mathrm{x}=0,0.08,0.17$ and 0.25$)$ : (a) as cast, (b) aged at $600^{\circ} \mathrm{C}$ for $3 \mathrm{~h}$ 
Table 1 Mechanical properties of as-cast and aged at $600^{\circ} \mathrm{C}$ for $3 \mathrm{~h} \mathrm{AlCrFeMnNiC}_{\mathrm{x}}(\mathrm{x}=0,0.08,0.17$ and 0.25$)$ alloys.

\begin{tabular}{lllll}
\hline State & $\mathrm{x}$ & $\begin{array}{l}\text { Yield stress } \\
\sigma_{\mathrm{y}}(\mathrm{MPa})\end{array}$ & $\begin{array}{l}\text { Compressive } \\
\text { Strength }(\mathrm{MPa})\end{array}$ & $\begin{array}{l}\text { Plastic strain } \\
\varepsilon_{\mathrm{p}}(\%)\end{array}$ \\
\hline \multirow{3}{*}{ As-cast } & 0 & 1402 & 2613 & 24.8 \\
& 0.08 & 1297 & 2959 & 30.6 \\
& 0.17 & 1338 & 2482 & 25.2 \\
Aged at & 0.25 & 1105 & 2931 & 27.8 \\
$600^{\circ} \mathrm{C}$ for $3 \mathrm{~h}$ & 0.08 & 1569 & 2424 & 18.5 \\
& 0.17 & 1264 & 3245 & 35.3 \\
& 0.25 & 1298 & 3155 & 31.2 \\
\hline
\end{tabular}

\section{Conclusions}

The experimental results indicate that introduction of carbon element into AlCrFeMnNi alloy could improve the mechanical properities of $\mathrm{AlCrFeMnNi}$ alloy, though it can not transform $\mathrm{BCC}$ phase to FCC phase. The results suggest that the addition of $\mathrm{C}$ elements can be a developing direction of high-entropy alloy. In addition, the concept of high-entropy alloy may be introduced into steel design to develop high-entropy alloy steel.

\section{Acknowledgements}

This work was financially supported by China National Natural Science Foundation (No. 51574162). SEM and XRD were made in the Instrumental Analysis \& Research Center at Shanghai University. The authors would like to express sincere thanks for their support.

\section{References}

[1] M. Herbig, M. Kuzmina, C. Haase, R.K.W. Marceau, I. Gutierrez-Urrutia,D. Haley, et al., Acta Mater. 83 (2015) 37-47.

[2] J.H. Li, M. Albu, F. Hofer, P. Schumacher, Acta Mater. 83 (2015) 187-202.

[3] Z.D. Zhao, Q. Chen, S.H. Huang, H.Y. Chao, Mater. Des. 31 (2010) 1906-1916.

[4] Y.Y. Li, K. Hu, X.Q. Li, X. Ai, S.G. Qu, Mater. Sci. Eng. A 573 (20) (2013) 245-252.

[5] J.W. Yeh, S.K. Chen, S.J. Lin, J.Y. Gan, T.S. Chin, T.T. Shun, et al., Adv. Eng. Mater. 6 (5) (2004) 299-303.

[6] S.C. Middleburgh, D.M. King, G.R. Lumpkin, M. Cortie, L. Edwards, J. Alloys Compd. 599 (2014) 179-182.

[7] Z. Wu, H. Bei, F. Otto, G.M. Pharr, E.P. George, Intermetallics 46 (2014)131-140.

[8] Z.Q. Fu, W.P. Chen, Z. Chen, H.M. Wen, E.J. Lavernia, Mater. Sci. Eng. A 619(2014) 137-145.

[9] Y. Zhang, T.T. Zuo, Z. Tang, M.C. Gao, K.A. Dahmen, P.K. Liaw, et al., Prog. Mater. Sci. 61 (2014) 1-93.

[10] M.A. Hemphill, T. Yuan, G.Y. Wang, J.W. Yeh, C.W. Tsai, A. Chuang, et al., Acta Mater. 60 (2012) 5723-5734.

[11] Y. Zhang, T.T. Zuo, P.K. Liaw, Y.Q. Cheng, Sci. Rep. 3 (2013) 1455.

[12] Y.F. Kao, S.K. Chen, J.H. Sheu, J.T. Lin, W.E. Lin, J.W. Yeh, et al., Int. J. Hydrog. Energ. 35 (2010) 9046-9059.

[13] H.Y. Chen, C.W. Tsai, C.C Tung, et al., Ann. Chim. Sci. Mater. 31(2006) 685-698.

[14] C.P. Lee, C.C Chang, Y.Y Chen, et al., Corros. Sci. 50 (2008)2053-2060. 
[15] W.Y. Tang, M.H. Chuang, H.Y. Chen, et al., Surf. Coat. Technol. 204 (2010) 3118-3124.

[16] L.C. Tsao, C.S. Chen, C.P. Chu. Mater. Des. 36 (2012) 854-858.

[17] S.T. Chen, W.Y. Tang, Y.F. Kuo, et al., Mater. Sci. Eng. A 527 (2010) 5818-5825.

[18] S.Z. Wei, J.H. Zhu, L.J. Xu, R. Long. Mater. Des. 27(2006) 58-63.

[19] B.S. Murty, J.W. Yeh, S. Ranganathan. High-Entropy Alloys. (2014). 